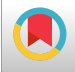

\title{
Pre- and Post- birth Causes of Acute Lymphoblastic Leukemia
}

\author{
Mehdi Shahriari, ${ }^{1}$ Mohammadebrahim Jafari, ${ }^{1}$ Mohammad Khalafi, ${ }^{1}$ Mehrdad Ramezani, ${ }^{1}$ \\ Massoumeh Maki, ${ }^{2}$ Fatemeh Hosseinpour Soleimani, ${ }^{3,{ }^{*}}$ Parinaz Khadem, ${ }^{4}$ Parastoo Ghorbani, ${ }^{5}$ \\ Maryam Allahverdi Khani, ${ }^{6}$ and Ehsan Shahverdi ${ }^{7,8}$ \\ ${ }^{1}$ Department of Pediatrics, Shiraz University of Medical Sciences, Shiraz, Iran \\ ${ }^{2}$ Department of Nursing and Midwifery, Falavarjan Branch, Islamic Azad University, Isfahan, Iran \\ ${ }^{3}$ Student Research Committee, Bushehr University of Medical Sciences, Bushehr, Iran \\ ${ }^{4}$ School of Allied Medical Sciences, Shahid Beheshti University of Medical Sciences, Tehran, Iran \\ ${ }^{5}$ Student Research Committee, Mazandaran University of Medical Sciences, Sari, Iran \\ ${ }^{6}$ Faculty of Medicine, Najafabad Branch, Islamic Azad University, Najafabad, Isfahan, Iran \\ ${ }^{7}$ Blood Transfusion Research Center, High Institute for Research and Education in Transfusion Medicine, Tehran, Iran \\ ${ }^{8}$ Blood and Cancer Research Center, Mahak Pediatric Cancer Treatment and Research Center, Tehran, Iran \\ "Corresponding author: Fatemeh Hosseinpour Soleimani, Student Research Committee, Bushehr University of Medical Sciences, Moallem St., Bushehr, Iran. Tel/Fax: \\ +98-773340089, E-mail: fa.hosseinpour73@yahoo.com
}

Received 2018 January 18; Revised 2018 April 08; Accepted 2018 April 11.

\begin{abstract}
Background: Acute lymphoblastic leukemia (ALL) is a malignancy of lymphoid progenitors in bone marrow, peripheral blood, and extra medullar, which accounts for $1 / 4$ of childhood cancers.

Objectives: Regarding the uncertainties of the exact causes of the disease and the importance of identifying risk factors of acute lymphoblastic leukemia, this study aimed at investigating the causes of pre- and post - natal birth in children with ALL.

Methods: This case - control study was performed on 156 patients with ALL and 85 patients without ALL in a 4 - year period in Ali Asghar, Shahid Faghihi, and Shahid Motahari Hospitals in Shiraz, Iran between January 2013 and March 2017. The student's t and Chi - square tests were used. To evaluate relationships between various variables, Pearson's or Spearman's correlation analyses were used. The data were analyzed, using the SPSS 16 software.

Results: Based on the findings of this study, the presence of Dawn's syndrome and familial history of leukemia and brain tumors were identified as risk factors for the incidence of ALL in children. There was no significant relationship with the history of abortion, radiation exposure, economic status, place of residence, birth rate, etc.

Conclusions: The results indicate that among pre- and post - birth causes, the presence of Down syndrome and familial history of leukemia and brain tumors were as risk factors for the incidence of ALL in children. Due to the fact that therapeutic protocols are useful for the treatment of ALL in children, the results of this study and similar studies can be effective in preventing and managing the disease in children.
\end{abstract}

Keywords: Cancer, Leukemia, Acute Lymphoblastic Leukemia

\section{Background}

Cancer is one of the most pivotal causes of mortality after cardiovascular disease in the world and was responsible for 8.8 million deaths in 2015. In 2017, approximately 1688780 new cancer cases and 600920 deaths due to cancer were reported in the United States and more than 30000 new cases are annually reported in Iran (1). Generally, proliferation and apoptosis imbalance results in cancer formation. Leukemia is characterized by the abnormal proliferation of immature hematopoietic cells in bone marrow; the prevalence of acute leukemia is more than chronic types (2). Acute lymphoblastic leukemia (ALL) is a malignancy of lymphoid progenitors in bone marrow, peripheral blood, and extra medullar, which can affect both children and adults (3). This malignancy accounts for 1/4 of childhood cancers with an increased prevalence between the ages of 2 to 5 years $(3,4)$. Although the precise causes of ALL progression are unknown, its relevance with Down's syndrome, Bloom's syndrome, ataxia - telangiectasia, and Nijmegen breakage syndrome, fanconi anemia, ionizing radiation or exposure to specific chemotherapy drugs is indicated $(3,5)$. Furthermore, in many cases, ALL is arisen from chromosomal abnormalities. However, chromosomal appearances are not the absolute causes of malignancy generation (5). Maternal reproductive history, using tobacco or alcohol by parents, exposure to pesticides, 
or solvents are likely factors, which increase the risk of this disease (3). Interestingly, some studies have demonstrated that ALL is associated with hygiene conditions and infectious agents. Herein, some studies have been demonstrated the correlation between hepatitis A and ALL (6). An investigation in 2003 indicated that maternal EBV infection is linked to ALL (7). Hence, we aimed at investigating the pre- and post - natal risk factors, which influence ALL stricken children. Since, the current therapeutic protocols in children are impressive, such studies will have prospective influences in the prevention and management of childhood ALL.

\section{Methods}

This case - control study was performed on patients with ALL picked from Ali Asghar, Shahid Faghihi, and Shahid Motahari Hospitals in Shiraz, Iran between January 2013 and March 2017. The convenience sampling was used as the sampling method. After obtaining written informed consent from all parents, information were collected from the patients' files. Also, patients' parents answered the prepared questionnaire, including questions about factors leading to increase the risk of this disease such as the age of diagnosis, pregnancy age, pregnancy course, child birth order in the family, maternal abortion history, history of stillbirth, economic and social situation, radiation exposure, patient habitat and distance to high voltage power pole, history of viral infections such as flu and chicken pox in patients before ALL diagnosis, family history of brain tumors and hematologic malignancies, and specific syndromes in the child. Eighty - five patients hospitalized with non - leukemic reasons were considered as a control group and studied by this questionnaire. Participants included children of 14 years or younger with newly diagnosed and immunophenotipically defined ALL. Cases with inadequate or duplicate information and lack of access to parents were excluded from the study.

\subsection{Statistical Analysis}

For the comparison between patient and control groups, student's t and Chi - square tests were used. To evaluate the relationships between various variables, Pearson's or Spearman's correlation analyses were used. Data were analyzed, using statistical package for social sciences (SPSS) version 16 (SPSS Inc. Chicago, IL) for windows. Pvalue $<0.05$ was considered significant.

\subsection{Ethical Considerations}

This study was approved by the medical ethics committee of Shiraz University of Medical Sciences with the unique ID of 99_1541. An informed consent form was signed by individuals. All the terms of the Helsinki declaration were considered and the personal information remained anonymous.

\section{Results}

Among the patient group, 94 males (60\%) and 62 female patients (40\%) and among the control group, 57 (67\%) were males and 28 (33\%) female. The average age of the children was 7.7 years and the median age was 7 years. In relation to the history of abortion and stillbirth or death of children among mothers of 156 patients with ALL, 29 (18.6\%) had a history of abortion. Compared to the control group, which was 13 cases (15.5\%), there was no significant difference $(\mathrm{P}=0.66$ and $\mathrm{OR}=1.25)$.

In conjunction with the economic situation among patients, $5 \%$ had a good socioeconomic status, $49.3 \%$ had a bad economic and social status, and $45.5 \%$ of them had a moderate socioeconomic status and in the control group, these values were $11 \%, 41 \%$, and $47 \%$, respectively. There was no statistically significant difference between the patient group and the control group $(\mathrm{P}=0.13)$.

The average age of mothers during pregnancy was 25.5 years. The minimum age was 13 and the maximum was 41 years, which were not significantly different from the control group.

Among the mothers of children with ALL, only 18 cases (11.53\%) had a history of disease during pregnancy, and in the control group, 8 mothers (9.4\%) were patient during pregnancy (Table 1$)$. This difference is not statistically significant $(\mathrm{P}=0.26$ and $\mathrm{OR}=1.26)$.

Table 1. Frequency Distribution of Disease History during Pregnancy in the Control and Patient's Mothers

\begin{tabular}{lccc}
\hline Disease & Patient & Control & No. \\
\hline Infectious disease & $7(38.8 \%)$ & $1(12.5 \%)$ & 8 \\
\hline Gynecologic disease & $5(27.7 \%)$ & $4(50 \%)$ & 9 \\
Chronic pain & $6(33.3 \%)$ & $3(37.5 \%)$ & 9 \\
Total & 18 & 8 & 36 \\
\hline
\end{tabular}

In relation to birth order, in the control group, the highest frequency was in the third group and the sixth birth order, and in the patient group, the highest frequency was related to the first birth order (Table 2).

Among the 156 mothers of the affected child, only 1 mother had a history of radiation during pregnancy, and others had no history of exposure to radiation. This difference was not statistically significant $(P=0.75)$.

Among the 156 mothers of ALL children, 20 cases (12.8\%) had a history of drug use during pregnancy. In compar- 


\begin{tabular}{lcc}
\hline \multicolumn{2}{l}{ Table 2. Frequency Distribution of Birth Order in the Control Group and Patients } \\
\hline Birth Order & Patient & Control \\
\hline $\mathbf{1}^{\text {st }}$ & $35(22.4 \%)$ & $18(21.2 \%)$ \\
$\mathbf{2}^{\text {nd }}$ & $32(20.5 \%)$ & $18(21.2 \%)$ \\
$\mathbf{3}^{\text {th }}$ & $26(16.6 \%)$ & $19(22.3 \%)$ \\
$\mathbf{4}^{\text {th }}$ & $16(10.2 \%)$ & $6(7 \%)$ \\
$\mathbf{5}^{\text {th }}$ & $24(15.4 \%)$ & $5(5.9 \%)$ \\
$\geq \mathbf{6}^{\text {th }}$ & $23(14.8 \%)$ & $19(22.1 \%)$ \\
\hline
\end{tabular}

ison, the control group had 9 cases (10.6\%) (Table 3); the difference between the control group and patients is not meaningful $(\mathrm{P}=0.2)$.

\begin{tabular}{|c|c|c|c|}
\hline Type of Drug & Patient & Control & No. \\
\hline Calmative \& antibiotic & $9(45 \%)$ & $5(55.5 \%)$ & 14 \\
\hline Oral contraceptive & $5(25 \%)$ & $0(0 \%)$ & 5 \\
\hline Unknown drugs or drug for abortion & $6(30 \%)$ & $4(44.5 \%)$ & 10 \\
\hline Total & 20 & 9 & 29 \\
\hline
\end{tabular}

Regarding exposure to radiation by the patient, 31 children $(20 \%)$ had a history of radiation and imaging before the diagnosis. This number was 85 in the control group (47\%), and the difference was statistically significant ( $\mathrm{P} \leq$ $0.05)$.

In relation to the magnetic field, 17 patients (11\%) and their families in the past 5 years have lived near high voltage power towers, compared to 8 cases in the control group (9.4\%). This difference is not statistically significant.

In relation to viral infections, 23 patients (21\%) out of 156 patients under study and 9 patients (10.6\%) of the control group had a history of chickenpox disease $(\mathrm{P}=0.05)$.

Regarding influenza, it should be noted that 44 (28.2\%) patients had a history of the disease, and 20 (23.5\%) had a history of influenza in the control group $(\mathrm{P}=0.5)$.

Among the patients, 21 cases (13.5\%) had a familial history of brain tumors or leukemia, and in the control group, these cases were observed in 3 (3.52\%) cases. This difference is statistically significant $(\mathrm{P}=0.025)$.

Of the patients, 2 cases (1.3\%) had Down syndrome, and no patients with Down syndrome was observed in the control group.

\section{Discussion}

This study was conducted to evaluate the risk factors and pre-and post - partum causes of ALL in children. Based on the findings of this study, the presence of Down syndrome and familial history of leukemia and brain tumors, and exposure to the radiation by cases were identified as risk factors for the incidence of ALL children. A study by Ripert et al., who reviewed the family history of cancer in ALL children, reported this variable as a risk factor that could contribute to the presence of ALL (8). The results of several other studies were consistent with this report (9-11). Furthermore, in other studies, the potential impact of autoimmune diseases on childhood cancers has also been reported (12-17). This indicates that a family history of cancer or immune system abnormalities may indirectly lead to ALL, but not as a major cause. In this study, Down syndrome was reported as one of the risk factors for ALL in children. The role of Down syndrome (trisomy 21), as a risk factor for the incidence of ALL children, has been shown in numerous studies, in which children with Down syndrome have a significantly higher risk of ALL as compared to children without it (18-22).

In the present study, there was no meaningful relationship between the birth order and ALL in children, which was similar to the findings of other studies (23-25). However, some studies have reported a rise in the birth order $(26,27)$ and some others reported a decrease in the birth order (28) as a risk factor for the incidence of ALL in children. The findings, although contradictory, have been interpreted according to the infectious assumptions of the causes of childhood leukemia, as the presence of larger sisters and brothers increases the chances of an increase in exposure to post - partum infectious agents (29). Some studies have suggested that maternal age and birth order are related to the underlying causes of childhood leukemia (30, 31 ), but we were not able to find such association, probably due to the small number of cases.

In this study, there was no significant relationship between the incidence of ALL in children and viral infections, which was consistent with the results of other studies (3234). Some studies have supported a role for EBV in EBV - associated Burkitt's lymphoma (35), but the low number of patients with virus infection in our study may be responsible for not creating a difference.

Previous studies did not show a significant correlation between the incidence of ALL children and radiography, $X$ rays, and living near high-pressure craters (36-38) were consistent with the results of this study. In other studies, there has been an association between ALL children and exposure to $\mathrm{X}$ - rays $(4,39)$. In relation to the $\mathrm{X}$ - ray image in this study, there was a significant difference, but in favor of the control group. It can be due to the type of diseases in the control group, which needs to be more radiographed.

Findings of various studies have shown an increased risk of ALL among mothers of advanced age with a history 
of abortion and stillbirth $(40,41)$. Other studies did not show a meaningful relationship between these two variables and the incidence of ALL children $(24,29,42)$. There is no significant relationship between the results of this study. In relation to the history of maternal morbidity and drug use and the risk of ALL children in this study, there is no significant relationship. The contradictions reported in the above variables may all be affected by a population and a low diversity of study.

Limitations of this study can be attributed to information gathering methods, particularly information remember by parents or family of patients. It is suggested that further studies be conducted to determine the effect of birth weight, viral infection, history of the disease, and drug use during pregnancy in the incidence of ALL in children.

\subsection{Conclusions}

The exact cause of leukemia is still unknown and scientists and physicians believe that a combination of genetic and environmental factors contribute to the disease. The data and results of this study show that among the causes and risk factors of pre- and post - natal risk, the presence of Down syndrome and family history of leukemia and brain tumors can be considered as risk factors for ALL in children.

It is urgent to treat the patients with acute leukemia immediately before bone marrow loss. The ultimate goal of this study and similar studies is to identify the best risk factors and causes for ALL, so that preventive measures can be taken on the basis of this information for children. Since the current treatment protocols in children are hopefully improved, such studies can have a significant impact on the prevention and management of ALL children.

\section{Acknowledgments}

None declared.

\section{Footnotes}

Authors' contributions: All authors equally contributed in study design, data collection, analysis, data interpretation, writing the report, and the decision to submit the paper for publication.

Conflict of Interest: There is no conflict of interest.

Financial Disclosure: There were no sources of funding or financial support for this study.

\section{References}

1. Amori N, Aghajani M, Asgarian FS, Jazayeri M. Epidemiology and trend of common cancers in Iran (2004-2008). Eur J Cancer Care (Engl). 2017;26(5). doi:10.1111/ecc.12449. [PubMed: 26811194].
2. Sampath D. MicroRNA in Leukemias. MicroRNA in Cancer. Dordrecht: Springer; 2013. p. 97-118. doi:10.1007/978-94-007-4655-8_7.

3. Pui $\mathrm{CH}$, Robison LL, Look AT. Acute lymphoblastic leukaemia. Lancet. 2008;371(9617):1030-43. doi: 10.1016/S0140-6736(08)60457-2. [PubMed: 18358930].

4. Mazloomi Tabrizi M, Arbabi Bidgoli S. Increased Risk of Childhood Acute Lymphoblastic Leukemia (ALL) by Prenatal and Postnatal Exposure to High Voltage Power Lines : A Case Control Study in Isfahan, Iran. Asian Pac J Canc Prev. 2015;16(6):2347-50. doi: 10.7314/apjcp.2015.16.6.2347.

5. Terwilliger T, Abdul-Hay M. Acute lymphoblastic leukemia: a comprehensive review and 2017 update. Blood Cancer J. 2017;7(6). e577. doi: 10.1038/bcj.2017.53. [PubMed: 28665419]. [PubMed Central: PMC5520400].

6. Smith MA, Simon R, Strickler HD, McQuillan G, Ries LA, Linet MS. Evidence that childhood acute lymphoblastic leukemia is associated with an infectious agent linked to hygiene conditions. Cancer Causes Control.1998;9(3):285-98. [PubMed: 9684709].

7. Lehtinen M, Koskela P, Ogmundsdottir HM, Bloigu A, Dillner J, Gudnadottir M, et al. Maternal herpesvirus infections and risk of acute lymphoblastic leukemia in the offspring. Am J Epidemiol. 2003;158(3):207-13. [PubMed: 12882942].

8. Ripert M, Menegaux F, Perel Y, Mechinaud F, Plouvier E, Gandemer V, et al. Familial history of cancer and childhood acute leukemia: a French population-based case-control study. Eur J Cancer Prev. 2007;16(5):466-70. doi: 10.1097/01.cej.0000243849.82232.cb. [PubMed: 17923819]. [PubMed Central: PMC2596893].

9. Infante-Rivard C, Guiguet M. Family history of hematopoietic and other cancers in children with acute lymphoblastic leukemia. Cancer Detect Prev. 2004;28(2):83-7. doi: 10.1016/j.cdp.2003.12.003. [PubMed: 15068830].

10. Perrillat F, Clavel J, Jaussent I, Baruchel A, Leverger G, Nelken B, et al. Family cancer history and risk of childhood acute leukemia (France). Cancer Causes Control. 2001;12(10):935-41. [PubMed: 11808713].

11. Smulevich VB, Solionova LG, Belyakova SV. Parental occupation and other factors and cancer risk in children: I. Study methodology and non-occupational factors. Int J Cancer. 1999;83(6):712-7. [PubMed: 10597183].

12. Woods WG, Robison LL, Kim Y, Schuman LM, Heisel M, Smithson A, et al., editors. Association of maternal autoimmunity with childhood acute lymphocytic-leukemia (all)-a case/control study. Proceedings of the american association for cancer research. philadelphia, USA.1987.251 p.

13. Westbom L, Aberg A, Kallen B. Childhood malignancy and maternal diabetes or other auto-immune disease during pregnancy. BrJCancer. 2002;86(7):1078-80. doi: 10.1038/sj.bjc.6600192. [PubMed: 11953852]. [PubMed Central: PMC2364171].

14. Till M, Rapson N, Smith PG. Family studies in acute leukaemia in childhood: a possible association with autoimmune disease. Br J Cancer 1979;40(1):62-71. [PubMed: 289405]. [PubMed Central: PMC2009963].

15. Perillat-Menegaux F, Clavel J, Auclerc MF, Baruchel A, Leverger G, Nelken B, et al. Family history of autoimmune thyroid disease and childhood acute leukemia. Cancer Epidemiol Biomarkers Prev. 2003;12(1):60-3. [PubMed: 12540505].

16. Ekstrom K, Hjalgrim H, Brandt L, Baecklund E, Klareskog L, Ekbom A, et al. Risk of malignant lymphomas in patients with rheumatoid arthritis and in their first-degree relatives. Arthritis Rheum. 2003;48(4):96370. doi: 10.1002/art.10939. [PubMed: 12687538].

17. Buckley JD, Gilchrist GS, Ruccione K, Sather HN, Woods WG, Hammond GD. Multiple sclerosis in mothers of children with acute lymphoblastic leukemia. Leukemia. 1989;3(10):736-9. [PubMed: 2779288].

18. Zwaan MC, Reinhardt D, Hitzler J, Vyas P. Acute leukemias in children with Down syndrome. Pediatr Clin North Am. 2008;55(1):53-70. x. doi: 10.1016/j.pcl.2007.11.001. [PubMed: 18242315]. 
19. Whitlock JA. Down syndrome and acute lymphoblastic leukaemia. $\mathrm{Br}$ J Haematol. 2006;135(5):595-602. doi: 10.1111/j.1365-2141.2006.06337.x.

20. Izraeli S. The acute lymphoblastic leukemia of Down Syndrome Genetics and pathogenesis. Eur J Med Genet. 2016;59(3):158-61. doi 10.1016/j.ejmg.2015.11.010. [PubMed: 26631987].

21. Hitzler JK, Zipursky A. Origins of leukaemia in children with Down syndrome. Nat Rev Cancer. 2005;5(1):11-20. doi: 10.1038/nrc1525. [PubMed: 15630411].

22. Bruwier A, Chantrain CF. Hematological disorders and leukemia in children with Down syndrome. Eur J Pediatr. 2012;171(9):1301-7. doi 10.1007/s00431-011-1624-1. [PubMed: 22113227]

23. Murray L, McCarron P, Bailie K, Middleton R, Davey Smith G, Dempsey $S$, et al. Association of early life factors and acute lymphoblastic leukaemia in childhood: historical cohort study. Br J Cancer. 2002;86(3):356-61. doi: 10.1038/sj.bjc.6600012. [PubMed: 11875699]. [PubMed Central: PMC2375228].

24. Kaye SA, Robison LL, Smithson WA, Gunderson P, King FL, Neglia JP. Maternal reproductive history and birth characteristics in childhood acute lymphoblastic leukemia. Cancer. 1991;68(6):1351-5. [PubMed 1873786].

25. Belson M, Kingsley B, Holmes A. Risk factors for acute leukemia in children: a review. Environ Health Perspect. 2007;115(1):138-45. [PubMed: 17366834]. [PubMed Central: PMC1817663].

26. Reynolds P. Birth Characteristics and Leukemia in Young Children. Am J Epidemiol. 2002;155(7):603-13. doi:10.1093/aje/155.7.603.

27. Ma X, Metayer C, Does MB, Buffler PA. Maternal pregnancy loss, birth characteristics, and childhood leukemia (United States). Cancer Causes Control.2005;16(9):1075-83. doi:10.1007/s10552-005-0356-9. [PubMed: 16184473].

28. Hjalgrim LL, Westergaard T, Rostgaard K, Schmiegelow K, Melbye $\mathrm{M}$, Hjalgrim $\mathrm{H}$, et al. Birth weight as a risk factor for childhood leukemia: a meta-analysis of 18 epidemiologic studies. Am JEpidemiol. 2003;158(8):724-35. [PubMed: 14561661].

29. Spector LG, Davies SM, Robison LL, Hilden JM, Roesler M, Ross JA. Birth characteristics, maternal reproductive history, and the risk of infant leukemia: a report from the Children's Oncology Group. Cancer Epidemiol Biomarkers Prev. 2007;16(1):128-34. doi: 10.1158/1055-9965.EPI06-0322. [PubMed: 17220341].

30. Stark CR, Mantel N. Maternal-age and birth-order effects in childhood leukemia: age of child and type of leukemia. J Natl Cancer Inst. 1969;42(5):857-66. [PubMed: 5254278].

31. Stark CR, Mantel N. Effects of maternal age and birth order on the risk of mongolism and leukemia. J Natl Cancer Inst. 1966;37(5):687-98. [PubMed: 4224604].

32. Perrillat F, Clavel J, Auclerc MF, Baruchel A, Leverger G, Nelken B, et al. Day-care, early common infections and childhood acute leukaemia: a multicentre French case-control study. Br J Cancer. 2002;86(7):10649. doi: 10.1038/sj.bjc.6600091. [PubMed: 11953850]. [PubMed Central: PMC2364194]

33. Neglia JP, Linet MS, Shu XO, Severson RK, Potter JD, Mertens AC, et al. Patterns of infection and day care utilization and risk of childhood acute lymphoblastic leukaemia. Br J Cancer. 2000;82(1):234-40. doi: 10.1054/bjoc.1999.0905. [PubMed: 10638995]. [PubMed Central: PMC2363184].

34. Morales-Sanchez A, Pompa-Mera EN, Fajardo-Gutierrez A, AlvarezRodriguez FJ, Bekker-Mendez VC, Flores-Chapa Jde D, et al. EBV, HCMV, HHV6, and HHV7 screening in bone marrow samples from children with acute lymphoblastic leukemia. Biomed Res Int. 2014;2014:548097. doi: 10.1155/2014/548097. [PubMed: 25309913]. [PubMed Central: PMC4189769]

35. Kim JH, Kim WS, Park C. Epstein-Barr virus latent membrane protein 1 increases genomic instability through Egr-1-mediated up-regulation of activation-induced cytidine deaminase in B-cell lymphoma. Leuk Lymphoma. 2013;54(9):2035-40. doi: 10.3109/10428194.2013.769218.

36. Roman E, Watson A, Beral V, Buckle S, Bull D, Baker K, et al. Case-control study of leukaemia and non-Hodgkin's lymphoma among children aged 0-4 years living in west Berkshire and north Hampshire health districts. BMJ.1993;306(6878):615-21. [PubMed: 8461811]. [PubMed Central: PMC1676930].

37. McLaughlin JR, King WD, Anderson TW, Clarke EA, Ashmore JP. Paternal radiation exposure and leukaemia in offspring: the Ontario case-control study. BMJ. 1993;307(6910):959-66. [PubMed: 8241906]. [PubMed Central: PMC1679166].

38. Kinlen LJ, Clarke K, Balkwill A. Paternal preconceptional radiation exposure in the nuclear industry and leukaemia and non-Hodgkin's lymphoma in young people in Scotland. BMJ. 1993;306(6886):1153-8. [PubMed: 8499814]. [PubMed Central: PMC1677644].

39. Shih TY, Wu J, Muo CS, Kao CH. Association between leukaemia and X-ray in children: a nationwide study. J Paediatr Child Health. 2014;50(8):615-8. doi: 10.1111/jpc.12605. [PubMed: 24909259].

40. Ross JA, Potter JD, Shu XO, Reaman GH, Lampkin B, Robison LL. Evaluating the relationships among maternal reproductive history, birth characteristics, and infant leukemia: a report from the Children's Cancer Group. Ann Epidemiol. 1997;7(3):172-9. [PubMed: 9141639].

41. Dockerty JD, Draper G, Vincent T, Rowan SD, Bunch KJ. Case-control study of parental age, parity and socioeconomic level in relation to childhood cancers. Int J Epidemiol. 2001;30(6):1428-37. doi: 10.1093/ije/30.6.1428.

42. Hassanzade J, Mohammadi R, Rajaeefard AR. [Risk factors in childhood lymphoblastic leukemia in Shiraz-Iran (2009): an epidemilogical study].J Gorgan Univ Med Sci. 2012;14(4):119-24. Persian. 